\title{
A cadeira como retrato do corpo humano: A representatividade do objeto para os designers/artistas
}

Adriana Sousa Fernandes é Mestre em Artes Visuais pela Escola de Belas Artes (2017-UFBA), Mestre em Educação, Artes e Gestão Cultural (2016-UIMP). Especialista em Iluminação e Design de Interiores pelo Instituto de Pós Graduação e Graduação (IPOG-2012). Graduada em Design de ambientes pela Escola de Belas Artes (UFBA-2008). Técnica em Edificações pelo Centro Estadual de Educação Profissional em Gestão Severino Vieira (CEEP-2014). Possui experiência como docente em instituições renomadas em Salvador-BA, como a Faculdade de Arquitetura da UFBA, IFBA e SENAI. Atualmente é professora da UNIVERSIDADE SALGADO DE OLIVEIRA CAMPUS SALVADOR (UNIVERSO), da UNIFACS - FEIRA DE SANTANA e professora substituta da Faculdade de Arquitetura da Universidade Federal da Bahia (FAU-UFBA).

$<$ drinandes@hotmail.com>

ORCID: 0000-0002-6655-2102
Resumo A cadeira assenta o corpo humano, identifica e reflete a memória de sua silhueta e dá significado àquilo que reproduz, algo ou alguém, pois existe uma presença que sugere uma imagem semelhante, um espelho. Partindo da questão "Como interpretar a semelhança formal da cadeira com o corpo?", a pesquisa tem por objetivo mostrar a cadeira como a própria expressão do corpo, que, por sua vez, é o fato gerador de sua forma. Para a realização deste estudo, foi utilizado o método comparativo e descritivo, a partir do qual foi feita uma investigação sobre o móvel produzido por designers-artistas, possibilitando uma comparação da morfologia adaptada ao artefato. Estas, possuem formas de corporeidade, com as quais fizemos comparações e sobreposições artísticas, demonstrando a utilização do corpo como imagem de valor universal, no qual o mesmo é um desejo da forma que se indicia pela cadeira, ocasionando novas percepções sensoriais.

Palavras chave Cadeira e corpo humano, Design-arte, Aspectos da forma. 
Suzi Maria Mariño possui Pós-Doutorado em Design pela Pontifícia Universidade Católica do Rio de Janeiro; Doutorado e Mestrado em Arquitetura e Urbanismo pela Universidade de São Paulo. Pós-Graduada em Metodologia do Ensino Superior, em Design de Produtos e em Atividade Física e Saúde. Atualmente é avaliadora do Sistema Nacional de Avaliação do Instituto Nacional de Estudos e Pesquisas Educacionais Anísio Teixeira, consultora "ad hoc' da Fundação de Amparo à Pesquisa do Estado da Bahia - FAPESB, do Ministério da Educação e Cultura - MEC e do Conselho Nacional de Desenvolvimento Científico e Tecnológico - CNPq. Foi presidente da Associação de Ensino Pesquisa de Nível Superior de Design do Brasil - AEnD-BR no triênio 2002/2005 e membro da Comissão Assessora de Avaliação da Área de Design - ENADE, do INEP/MEC no período de 2006 a 2015. Professora de Ikebana (Arte oriental) da Fundação Mokiti Okada; Professora Titular da Universidade do Estado da Bahia e Professora Associada da Universidade Federal da Bahia. Professora permanente do Programa de Pós-Graduação em Artes Visuais - PPGAV da Escola de Belas Artes da UFBA. Professora de Ergonomia e Metodologia Cientifica em Pós-Graduações em Medicina do Trabalho, Enfermagem do Trabalho e Engenharia de Segurança. Professora de Ergonomia, Metodologia do Projeto em Design e Metodologia Cientifica em Pós-Graduações de Design Estratégico, de Moda, Produto e Interiores. Atua na área de Design, com ênfase em Ergonomia.

<suzimarino@gmail.com>

ORCID: 0000-0001-8869-2299

\section{The Chair as a portrait of human Body: The Representation of the Object to the Designers-Artists}

Abstract The chair seats the human body, identifies and reflects the memory of its silhouette and gives meaning to what it reproduces, something or someone, for there is a presence that suggests a similar image, a mirror. Starting from the question "How to interpret the formal similarity of the chair with the body? ", This paper aims to show the chair as the real expression of the body, which, in turn, is the fact that generates its form. For the accomplishment of this study, the comparative and descriptive method was used, from which an investigation was made on the furniture produced by designers-artists, allowing a comparison of the morphology adapted to the artifact. These have forms of corporeity, with which we have made comparisons and artistic overlays, demonstrating the use of the body as an image of universal value, in which it is a desire of the form that is indicated by the chair, causing new sensory perceptions.

Keywords Chair and human body, Design-art, Aspects of form. 
Maria Virginia Gordilho é artista visual, Professora da EBA - UFBA. Realizou exposições individuais e coletivas em espaços culturais no Brasil, na Europa, África, África do Sul e atuou como artista-curadora em vários projetos. Premiada com bolsas de estudos (2001/2002) para o Programa de Cooperación Interuniversitaria Interdisciplinar de Escultura e Nuevas Tecnologias, na UPV - Universidade Politécnica de Valência. Participou do projeto Frauenkulturforum, nas cidades de Essen e Hagen na Alemanha e em Johannesburg (2004) e Nairóbi (2005) integrou o projeto itinerante Visible Visions, com o apoio da UNESCO. Foi premiada como artista residente no Instituto SACATAR(2004), com publicação Edital FAPESB ( 2005/2007, Prêmio Curadoria Edital FUNCEB(2007). Sob o apoio de bolsa da CAPES (PICD), realizou seus estudos no Doutorado (2000/2003) É autora de vários artigos e dos livros Cantos, Contas e Contos: Uma trama às águas como lugar de passagem, resultado parcial da sua tese de Doutorado; Onde se esconde o cinza luminoso? e Onde as casas se vestem de cá?, ambos contos para todas as idades, aprovados pelo Conselho Científico da EDUFBA. É Presidente da diretoria da ANPAP - Associação Nacional de Pesquisadores em Artes Plásticas e do Conselho diretor do Instituto Sacatar. Em suas pesquisas, tece reflexões prático-teóricas, tendo como campo de percepção as raízes culturais afro-indígenas brasileiras e a experimentação com distintos materiais. Integra o grupo de pesquisa MAMETO- "MAtéria, MEmória e conceiTO. em poéticas visuais contemporâneas", certificado pelo CNPq, do qual é líder. <vigagordilhoufba@gmail.com> ORCID: 0000-0002-6120-6745

\section{Introdução}

Dentre os inúmeros projetos que desafiam a capacidade lógico-criativa de um designer, a cadeira ocupa um lugar de destaque, uma vez que, muito mais do que um simples objeto de funcionalidade definida, ela se apresenta numa relação entre produto e usuário criada por uma interlocução entre o corpo e a forma adotada. Acredita-se que o esboço corpóreo é uma referência intuitiva do ser humano, que busca um suporte para transpor suas experiências intimistas cuja forma seja capaz de expressar a silhueta ideal, numa obsessão por curvas sinuosas e orgânicas deslocadas para um móvel.

Assim, a cadeira, que vinha sendo analisada por diversos autores pelo viés da ergonomia e (ou) da funcionalidade, é estudada aqui com uma significância emocional, pois o designer está centrado no indivíduo, buscando de sua identidade, seu significado e sua experiência. Ela constitui um signo capaz de transmitir valores sensíveis e emocionais, utilizados como atributos do produto, tendo o corpo como retrato para a sua forma. Trago o vocábulo retrato no sentido de imagem (imaginária) de uma pessoa, que se substancializa através da cadeira, marcando a silhueta que induz o antropomorfismo do artefato.

Nesse sentido, esta pesquisa se reveste de uma relevância acadêmica, por promover um intercâmbio entre o design e a arte, no qual a criação plástica, formal e visual, possibilita uma inovação projetiva de linguagem através de um olhar atento das formas corporais acentuadas na cadeira, correlatadas com o formato humano.

\section{O Corpo Humano Retratado na Forma da Cadeira}

Para propiciar melhor entendimento do corpo como retrato, na forma da cadeira, trazemos o exemplo da performance de Merce Cunningham, intitulada Antic Meet (Figura 1), filmada em 1964. Trata-se de uma notável ilustração de como a cadeira pode funcionar como expansão do corpo, ampliando a fronteira entre o que seria o objeto e o ser humano. Em Antic Meet, a cadeira funciona como um suporte, proporcionando a realização de novos movimentos, quebrando o paradigma do retilíneo e fazendo o corpo alcançar uma infinidade de possibilidades coreográficas. Gera-se, assim, uma nova linguagem que estabelece uma permuta entre os sentidos orgânicos e inorgânicos, no qual a cadeira é o orgânico e o corpo assume a forma inorgânica. Diante dessa inversão, nota-se que a cadeira e o corpo não devem ser considerados como coisas distintas, uma vez que ambos constituem o reflexo de sua forma. Para Faria (2009), a presença da cadeira em Antic Meet está significando a suspensão temporária de uma ação corporal em prol de uma ação futura e abriu espaço para as artes do corpo.

"A leitura da natureza a partir da geometria é a cena imaginária em que a menção do corpo é sempre o enunciado de desejo da forma; o que significa uma imagem totalizada reconhecível no espelho".(MATESCO, 2009, p. 14) 


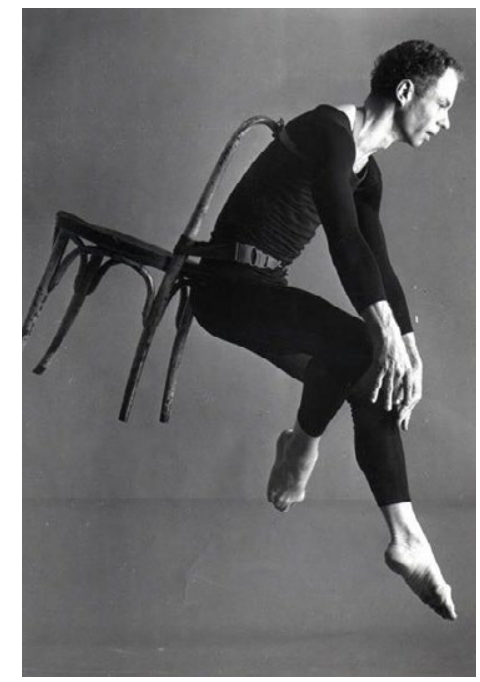

Fig 1. Dançarino Merce Cunningham Fotografia de Richard Rutledge. Fonte: Center (2012)

Fig 2. O corpo de Merce Cunningham como cadeira.

Fonte: Elaborado pela autora
O desejo pela forma da cadeira é explícito na imagem, na qual o movimento se espelha na cadeira e cria uma relação casual que complementa com uma ilusão de reflexo. Para Faria (2009 apud RIBEIRO, 1994, p. 5), as cadeiras servem de "instrumento de medida e de configuração do humano", como também são objetos de metamorfose das qualidades do humano, que "procura aproximar o corpo de si mesmo, em um percurso onde há uma aproximação do corpo a uma realidade social" (FARIA, 2009, p.5). São valores expressivos e comunicativos do corpo que abrem horizontes e que permeiam por diversas áreas. Aqui, escolhemos o design, o produto, a cadeira, que toma forma através do corpo e é nele que enxergamos o objeto.

Se, hipoteticamente, retiramos a cadeira da fotografia (Figura 2), pode ser que o nosso cérebro, dada a posição do coreógrafo, interprete a forma literal de uma cadeira, composta pela matéria corpo.
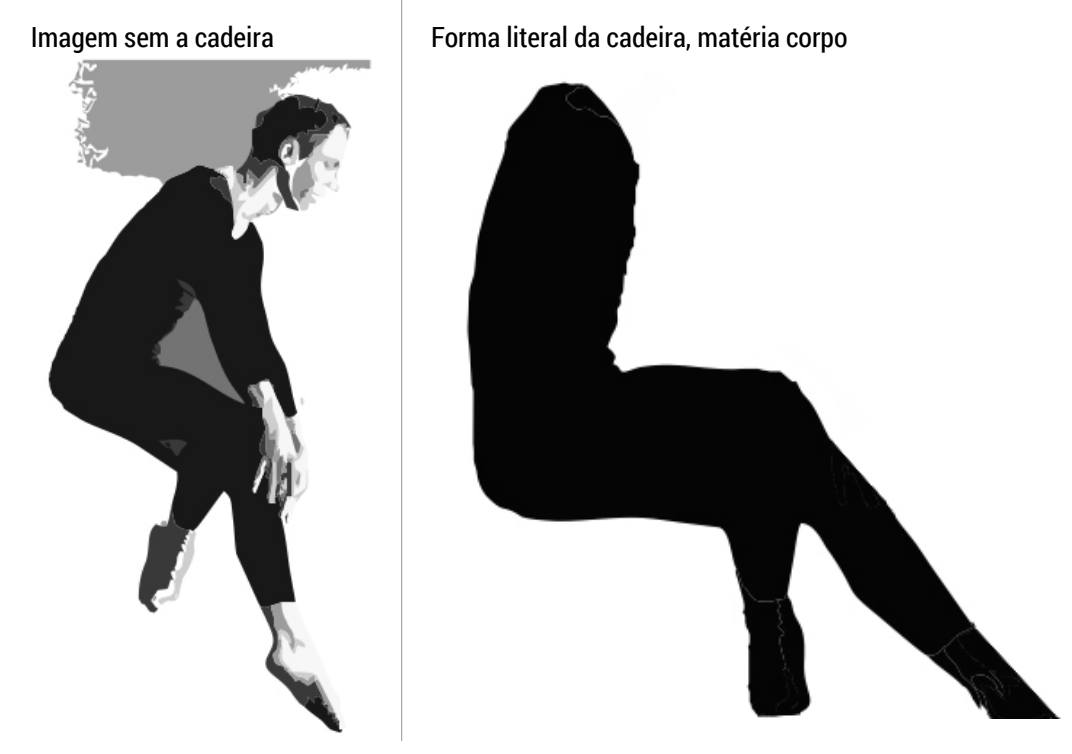

Esta matéria é a substância que dá forma à cadeira, que reconstrói um novo olhar, no qual o corpo desenha a cadeira com suas curvas sinuosas, naturais.

Faria (2009 apud Ribeiro, 1997, p.4) afirma que a cadeira "[...] introduzida "no espaço da cena", tanto na dança quanto no teatro, nos traduz um "hiper-realismo" associado ao que é humano, assim como todos os rituais a ela associados". A humanização que atribuímos à cadeira se faz recorrente no momento em que o objeto se torna parte da vida, como ser inanimado que é forma, forma de corpo, e "dialoga" com o cotidiano, unindo-se a seu usuário. Como resultado, "a cadeira é ressignificada e indaga sobre a condição do homem diante da realidade, sobre o sujeito e objeto de um legado que transita entre o racional e o fantástico." (FARIA, 2009).

Aqui colocamos a cadeira, num processo de transfiguração e metamorfose, como um corpo etéreo, volátil, desmaterializado, que representa a ideia de cadeira e, ao final, adquire forma e significação. 


\section{A Representatividade do Objeto para os Designers/Artistas}

Quadro 1. Linha do tempo da corporeidade da cadeira.

Fonte: Elaborado pela autora
De acordo com o percurso do estudo, entendemos que o corpo e a cadeira se entrelaçam com uma linguagem única, finalizada em um objeto que carrega significados gerados pelo seu designer ou através da interlocução do seu usuário. Cria-se, assim, uma espécie de vida anônima, com um sujeito-corpo que interage no cotidiano humano. Assim, analisamos quatro cadeiras, apresentadas no Quadro 1, como linha do tempo de sua corporeidade. No final deste artigo, utilizando o método comparativo (Quadro 2), investigamos o objeto cadeira e seu designer-artista, comparando-a com a forma do corpo humano, ressaltando as diferenças e similaridades entre cadeira e corpo e tendo sempre como norte seu contexto histórico.

A importância do significado da cadeira e da forma para a concepção da sua construção estão presentes nos Estudos a seguir. Foram traçados croquis para cada artefato, seguindo-se um padrão esquemático a partir do exemplo encontrado na cadeira La chaise de Charles e Ray Eames, que foi inspirada em uma escultura de um nu feminino do artista Gaston Lachaise.

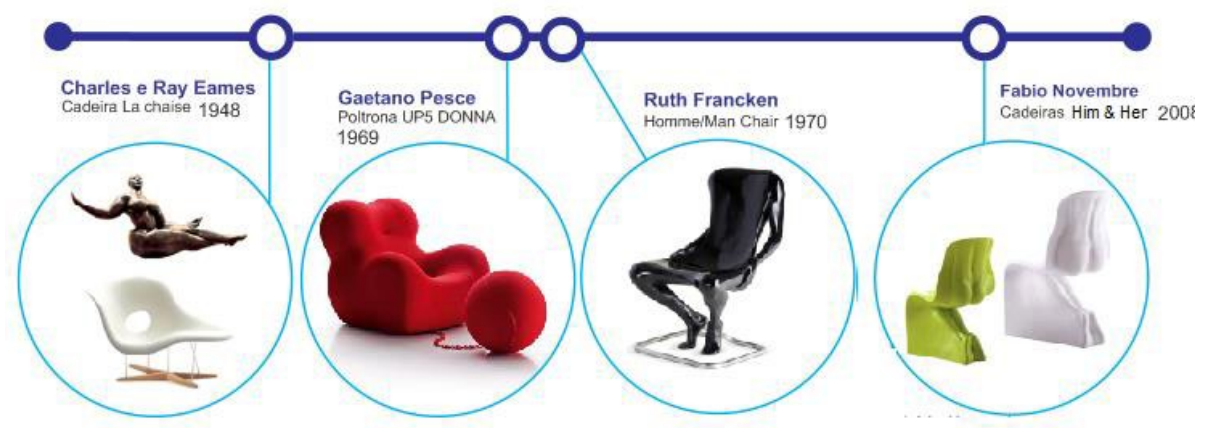

\section{Charles e Ray Eames - Cadeira La chaise (1948)}

O casal Charles e Ray Eames formou uma dupla de designers dos mais influentes do século XX, rompendo as contradições e as formas engessadas do mundo do design, bem como trazendo uma nova maneira de pensar a profissão, expandindo horizontes para multimídia, arquitetura, design gráfico, fotografia e cinema. Tais desenvolturas eram esperadas em alguém como Charles, que teve contato, quando criança, com "o sistema Froebel, método pedagógico pioneiro que estimulava as crianças de jardim de infância a brincar com blocos de madeira de formas geométricas" (STUNG, 2001, p. 11), estimulando seu senso espacial perante a construção das formas. E Ray, que sempre teve talento também precoce para a arte, frequentou aulas de dança e sempre teve um olhar voltando para o cinema. A união dos dois reuniu o que era necessário para um grande êxito no campo visual: a experiência em engenharia e construção e a experiência de cor, estrutura e forma. 
Charles nasceu em 1907 na Saint Louis, uma cidade independente, localizada no estado americano do Missouri, e Ray nasceu em 1912 na cidade de Sacramento, que é a capital do estado norte-americano da Califórnia, mas só se conheceram em Cranbrook, uma cidade do Canadá. Apesar de serem cidades distintas, suas vidas acabaram se cruzando quando Charles começou a lecionar na Academy of Art em Detroit e, assim, retornaram à Califórnia onde se casaram e montaram o seu primeiro escritório de design (STUNG, 2001, p.13).

Segundo Stung (2001), Charles estudou na Faculdade de Arquitetura da Washington University, mas não se formou devido às suas ideias radicais, que iam de encontro às correntes em vigor. Mas sempre se considerou um arquiteto, mais do que um design. Ray ingressou na Art Students League e se encontrou no mundo das artes. Fez parte do grupo American Abstract Artists, expondo em grandes galerias como as de Manhattan.

A exploração de materiais foi um dos pontos-chave para o sucesso do casal na área de móveis, principalmente as cadeiras. Iniciaram seus experimentos com a madeira compensada, ganhando o primeiro prêmio no concurso Organic Design in Home Furnishings, do Museum of Modern Art e não pararam, procurando superar derrubar o obstáculo desse material, que se quebrava em ângulos agudos. E, com a exploração desse material, até para o exército, na produção de talas, adquiriram a experiência necessária para alcançar o nível que conseguiram ao criar diversas cadeiras do tipo concha. Ao final, perceberam que elas não eram funcionais, por serem passíveis de quebra a qualquer momento.

Carregando uma filosofia de que o bom design deve ser accessível a todos, novos materiais foram surgindo. 0 plástico reforçado com fibra de vidro resolvia o problema das cadeiras do tipo concha, as quais, pelo seu formato, garantiam economia, pois não possuíam detalhes e eram feitas em peças únicas, permitindo o empilhamento. 0 metal, nesse período, era uma escolha confortável e entrava em conjunto com o plástico.

O plástico foi considerado um material futurista, pois sua flexibilidade abria novas possibilidades, principalmente para materializar as formas orgânicas, com curvas sinuosas. Charles e Ray Eames produziram, segundo o Design Museum (2011), uma das primeiras cadeiras de plástico com superfície externa exposta, a La Chaise, que participou do concurso internacional de design de móveis de baixo custo do Museu de Arte Moderna de Nova York em 1948. A cadeira é composta por fibra de vidro, com uma base cromada e pés de carvalho natural (Figura 3). Além de exibir uma cativante elegância, permite várias posições de sentar e de reclinar. Devido à sua complexidade, a cadeira La Chaise não foi produzida quando foi criada; só foi possível sua produção em 1996, pela Vitra Internacional.

A partir da cadeira La Chaise, o design ganha possibilidades ainda sem limites para a exploração da forma, pois é através dela que começam a surgir diversas cadeiras de formas orgânicas que se assemelham ao corpo. Ela é considerada um ícone para o design orgânico. Podemos observar atra- 


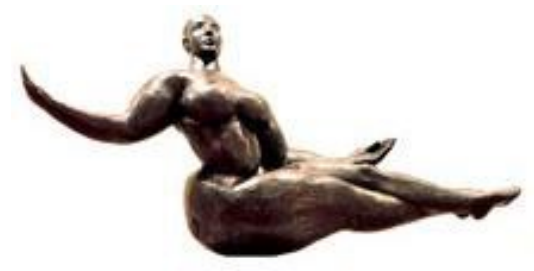

vés da escultura Floating Figure (figura flutuante), na Figura 3, que ela foi a inspiração para a criação dessa cadeira, cujo nome se refere tanto à função quanto à escultura, a qual, segundo o design imaginou, iria se moldar perfeitamente à cadeira. (STUDIOS, 2017)

Essa escultura é do artista espanhol Gaston Lachaise, cuja suas obras são, na sua maioria, corpos femininos com partes exageradas. Segundo Moma (2004), elas recordam as formas inchadas das figuras paleolíticas que representam fertilidade, como também alongam a proporção clássica do corpo, arredonda os músculos, a massa e a altura, criando uma harmonia, com uma cintura esbelta. 0 mesmo autor ainda ressalta que a artista expressa, através de sua arte, a glorificação do ser humano, do corpo humano e do espírito humano.

Essa exaltação do corpo transparece também na própria cadeira, caracterizada como personalidade por diversos autores. Como já foi destacado, ela "exala tanta vida e completude quanto qualquer outro ser vivo. Ela é um ser vivo" (DESIGN MUSEUM, 2011, p. 55)

O corpo aparece na cadeira de forma verdadeira e clara (Estudo 1), molda e lhe dá forma, transformando-a num "ser vivo"; ao lhe dar vida, constrói uma alma humana que condiciona e atrai o seu consumidor. Essa observação para nós foi preciosa, pois ressaltamos que, a partir dessa análise em particular, encontramos o foco do objeto desta pesquisa, o que, decerto, viabilizou acentuar a relação do corpo como retrato da cadeira.

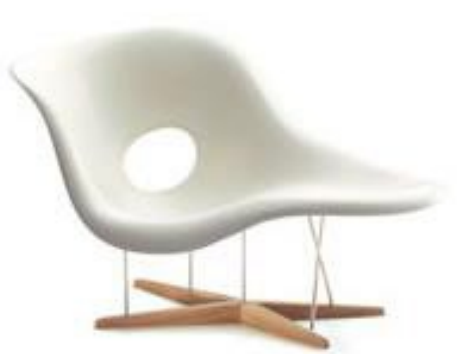

Fig 3. Linha do tempo da corporeidade da cadeira.

Fonte: Studios (2017).

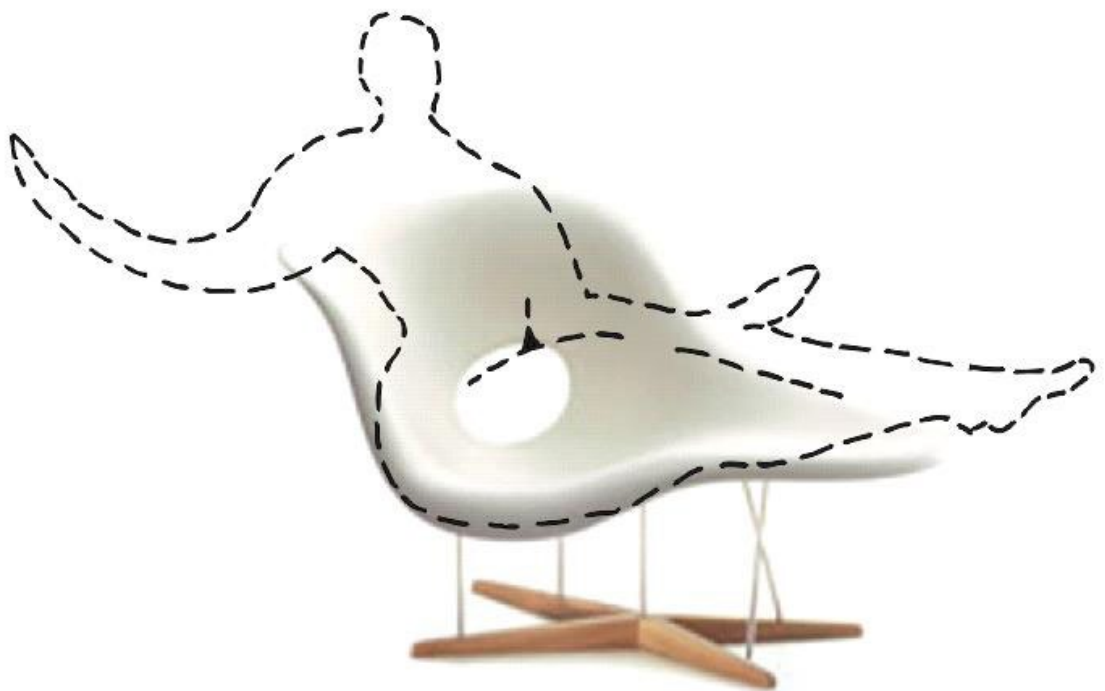

Fig 4. Estudo 1, cadeira La chaise (1948).

Fonte: Elaborado pela autora. 


\section{Gaetano Pesce - Poltrona UP5 DONNA (1969)}

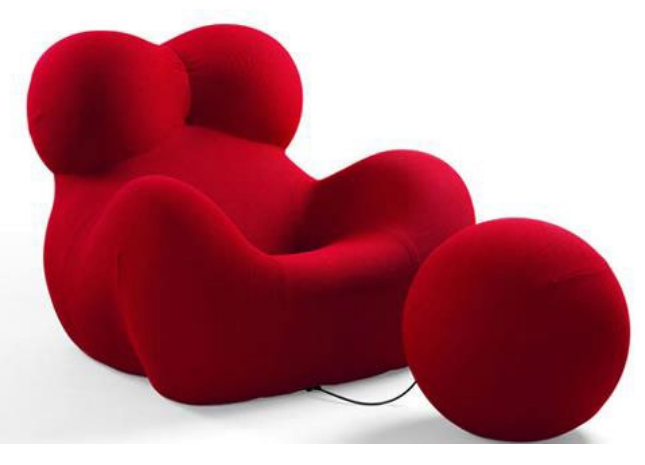

Fig 5. Poltrona UP5 DONNA (1969). Fonte: Giu (2012).

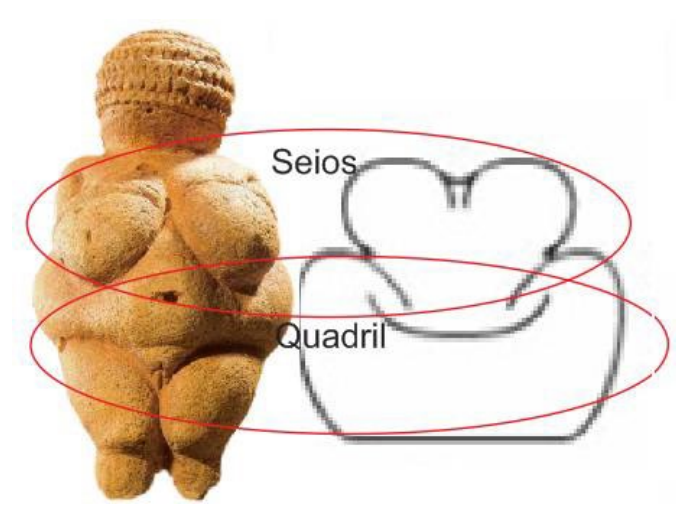

Fig 6. Comparação da Poltrona UP5 com a Vênus de Willendorf.

Fonte: Elaborada pela autora.

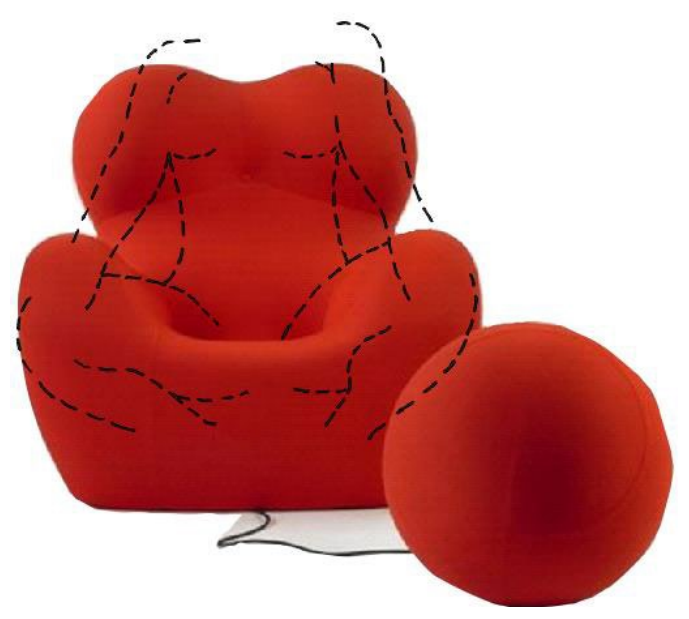

Fig 7. Estudo 2, Poltrona UP5 DONNA (1969). Fonte: Elaborado pela autora.
Gaetano Pesce é multifacetado, um arquiteto e design que percorre áreas como arquitetura, planejamento urbano, interior e design industrial. Nascido na província italiana La Spezia, em 1939, vive atualmente em Nova York.

Segundo Corsini (2015), Pesce estudou arquitetura na Universidade de Veneza entre 1958 e 1963 e participou do Gruppo N, um coletivo inicial preocupado com a arte programada modelada após a Bauhaus.

Seu trabalho é apresentado nos museus mais importantes do mundo, como MoMA (The Museum Of Modern Art), Metropolitan Museum de Nova York, Victoria and Albert Museum em Londres, o Centro Pompidou, em Paris, o Museu Alemão do Vitra Design e o Museu Montreal of Art, recebendo diversos prêmios: Prêmio Chrysler para Inovação e Design em 1993; o de Arquiteto e Wohnen Designer do Ano em 2006; e o Lawrence J. Israel do Fashion Institute of Technology em Nova York em 2009 (CORSINI, 2015).

É um profissional que procura inovar através da pesquisa de materiais e tecnologia, abusando das cores, o que resulta em inovação para a forma do produto. Como exemplo de aplicação dessas constantes explorações, temos a Poltrona UP5 DONNA (Figura 5), desenvolvida para a B\&B Itália, que faz parte dos sete modelos da série UP. Comprimida em um décimo de seu tamanho total, a Up5 se expandia completamente quando a embalagem a vácuo era rompida. Pesce a descreve como móvel da transformação (DESIGN MUSEUM, 2010, p. 72).

A UP5 acompanha a UP6, um pufe chamado de Otomana, em forma de esfera, que simboliza a mulher sujeita à sociedade, sua repressão, uma metáfora para a "mulher com bola e corrente" (GIU, 2012).

Apesar de moderna, a cadeira UP5 carrega uma carga ideológica profunda. $O$ pufe que está preso à cadeira por um fio, ou, em outras versões, por uma corrente, expressa todo o condicionamento social, político, religioso, dentre outros, que prendem a mulher a certas condições impostas, tentando privá-la de gozar sua plenitude.

As formas geométricas e curvilíneas marcam a presença do corpo feminino que acolhe, que envolve em um "abraço uterino" (GIU, 2012). Além de demonstrar sensualidade, ela se revela confortável por ser constituída de espuma de poliuretano moldada com tecido elástico, dotando-a de um conforto diferenciado, descrito por Giu (2012):

\footnotetext{
A cadeira UP5 marca o feliz encontro entre arte e design. A forma envolvente do assento e do encosto parece moldar-se em torno do corpo, procurando uma integração perfeita. Criado em uma relação dialética e perfeitamente calibrada. (GIU, 2012)
}

A UP5 mais a UP6 se transformaram em ícones entre os móveis modernos, ganhando vários nomes, como "Big Mama", "Blow Up", e se tornando um objeto de desejo. 
A presença de aspectos físicos femininos na cadeira é explícita. Segundo o próprio designer, ela foi projetada para ter o formato das estatuetas primitivas que representavam a fertilidade, como a conhecida Vênus de Willendorf (Figura 6), datada de 2500-2000 a.C., que possui formas volumosas, principalmente para os seios. Pode-se observar a presença desse volume no encosto da cadeira e também no assento, que representa o quadril.

A antropomorfia presente na poltrona atinge uma forma perturbadora sobre os costumes e hábitos de uma mulher, que no Estudo 2, foi elaborada pelo movimento corpóreo de uma "mulher com perna aberta", mais uma conotação que se pode visualizar no seu formato, que se encaixa em preceitos referentes à sensualidade, como a percepção da sexualidade.

\section{Ruth Francken - Homme/Man Chair (1970)}

As formas da cadeira muitas vezes remetem a partes do corpo humano, pois ela "tem pernas e braços, às vezes até cotovelos, joelhos e pés, o encosto lembra as costas, o assento é firme como o quadril. " (MUSEUM, 2011, p. 06), mas, de uma maneira geral, as cadeiras possuem o formato pressuposto de alguém sentado e, por isso, se torna tão atrativa para a ação do sentar.

Quando a cadeira, literalmente, abrange todos os aspectos de partes do corpo humano, ela adquire um poder ainda maior de ostentação, de presença do corpo, como vemos na Figura 8, da artista-designer Ruth Francken, que se utiliza da cadeira para esculpir um corpo sentado, não deixando o objeto perder sua função de acomodar o corpo, transformando o próprio quadril em assento. Entretanto, a cadeira adquire um aspecto de expressão artística que envolve um curioso afastamento entre o consumidor e o objeto, onde se subentende, que é uma obra de arte e, por assim dizer, não pode ser tocada.

Em 1960, em plena era do plástico, a produção em massa transformava o comportamento das pessoas, e o acesso barato aos produtos criou uma mentalidade favorável ao descartável, ao viver o imediato, que condicionava a criação dos móveis, principalmente as cadeiras.

Em 1964, segundo Bartoletti (2017), Francken abandonou a pintura para produzir objetos, continuando a usar uma linguagem clara, eficaz e simbólica, criando um repertório no espírito de revolta e engajamento político, preferindo falar de objetos ao invés de esculturas. Essa cadeira é uma declaração poderosa e única e faz parte da série Objekte (1967-76), que incorporou objetos cotidianos e referências à cultura pop, que caracteriza as expressões culturais em sua produção midiática.

A cadeira incorpora o seu discurso em um molde de gesso de um corpo masculino, tomado como modelo para a fundição de poliéster. A Galerie Boutique, propriedade de Eric e Xiane Germain, produziu, pela primeira vez, a cadeira Homme/Man (Figura 8), porque correspondia à sua visão de criar um espaço para aqueles que querem viver de uma forma alternativa, em que obras de arte, vídeos, fotos e objetos coexistiam com a chamada 


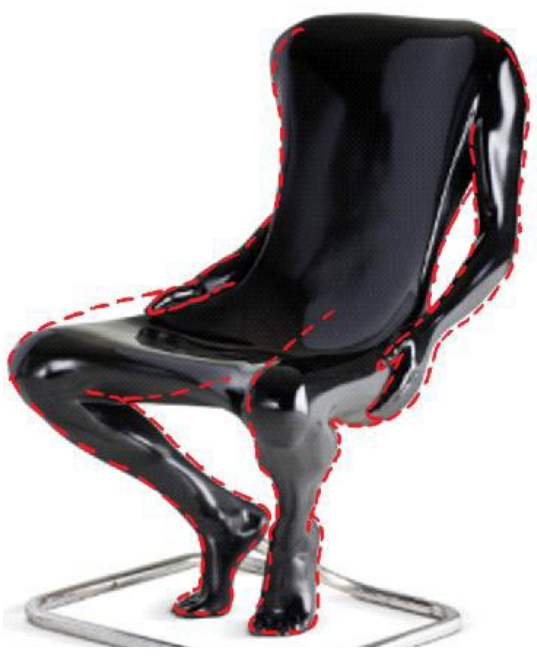

Fig 9. Estudo 3, Homme/Man Chair, Ruth Francken (1970)

Fonte: Elaborado pela autora. cultura pop, que possui fluxos de aproximações e diferenças reunidos em um mesmo ambiente.

\footnotetext{
A característica do assento em possuir as proporções do corpo humano sugere, de modo especial, uma fisicalidade e uma presença humana imanente a esse objeto que o reporta mais diretamente ao homem. Mesmo próximos a uma cadeira vazia, temos a sensação de uma "presença ausente". (CORRÊA; SILVA, 2013, p.14)
}

De um modo geral, a cadeira irá sempre refletir uma similaridade peculiar com o ser humano, pois o corpo é seu molde e sua razão de existir para tal função. A cadeira-escultura (Figura 8) traz exatamente esse recorte, em que seus discursos verbais (políticos) estão presentes na própria vida da designer-artista Ruth Francke, que cria uma imagem de um corpo transportado para o objeto cadeira, unindo os materiais industrializados com uma poética narrada por uma cadeira, signo de autoridade e poder. Essa cadeira nos faz retomar o exemplo que demos do dançarino Merce Cunningham, cujo corpo desenvolve um movimento idealizador de uma cadeira, como acontece e se materializa com essa criação de Ruth Francke, que pulsa o corpo como estrutura que forma a cadeira.

Acreditamos que, em ambos exemplares, a linguagem da forma seria determinada pela presença do desenho do corpo ou sua ausência, as quais condicionam significados e interligações significativas no usuário, refletindo-se num relacionamento direcionado ao objeto, ou ao dançarino, pois ambos, na nossa apreciação, teriam a cadeira como um retrato do corpo humano.

\section{Fabio Novembre - Cadeiras Him \& Her (2008)}

Fábio Novembre é um designer-artista que se caracteriza por conceitos inovadores, trazendo, em suas criações, uma grande carga poética, que acarreta discussões sociais e culturais.

Nascido em Lecce, 1966, a principal cidade da península Salentina, na Itália, mudou-se para Milão para se formar em arquitetura. Em 1992, frequentou o curso de Cinema na Universidade de Nova York. Segundo Cappellini (2017), tornou-se famoso através de projetos de design para restaurantes, discotecas e lojas, abrindo, em seguida, seu estúdio em Milão e estreitando parcerias, nesse mesmo período, com as principais empresas, como Cappellini, Dríade, Meritalia, Flaminia e Casamania.

Também havia o interesse em projetar showrooms e boutiques para as melhores marcas, não deixando de lado seu diferencial - os conceitos que conduziam a criação e transformavam-na em poesia, como a coleção masculina Tommy Hilfiger Tailored, da Pasquale Formisano (Figura 10). 


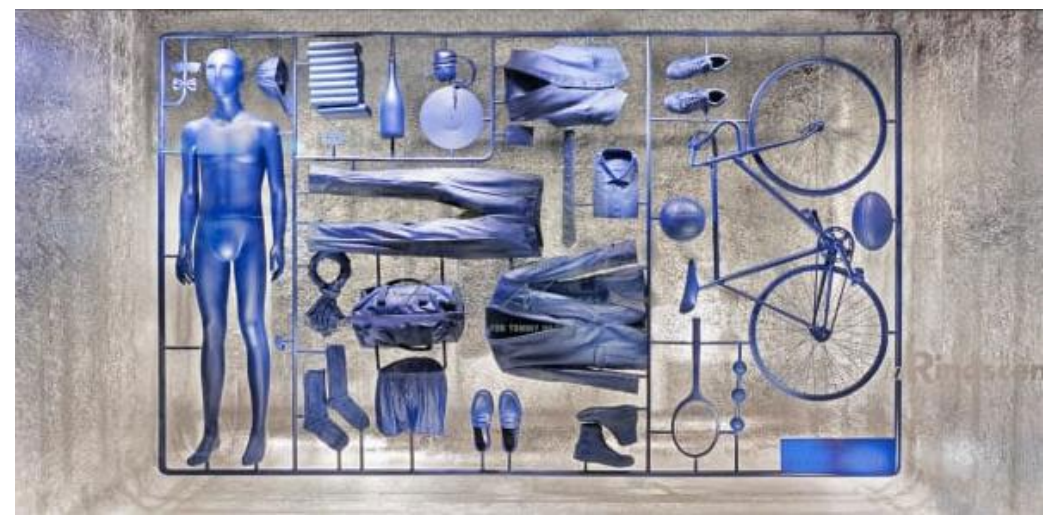

Fig 10. Coleção masculina da Tommy Hilfiger Tailored.

Fonte: Divisare (2017).

Intitulada "Eu tenho um estilo de vida", a instalação é a interpre-

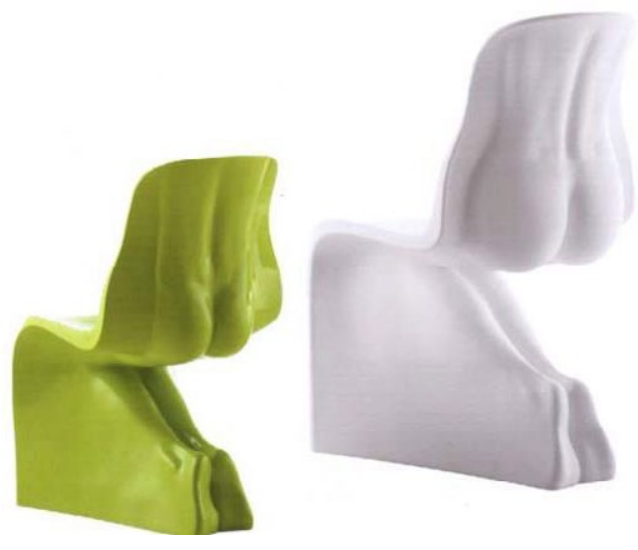

Fig 11. Cadeiras Him \& Her (2008)

Fonte: Novembre e Casamania (2017) criativa de Novembre do guarda-roupa de um homem, com uma tubulação em azul que interliga e incorpora as peças da coleção, sobre a qual Novembre conceitua: "Não há instruções de montagem para a nossa personalidade. Nós construímos nosso kit modelo dia a dia, ouvindo bons conselhos e seguindo bons sonhos."

O corpo possui um formato que muito atrai o designer-artista Fábio Novembre, que propõe, em seus objetos, formas corpóreas e linhas elegantes e inovadoras. Como exemplo, temos as cadeiras Him \& Her (Figura 11) que se assemelham a silhuetas masculinas e femininas.

Novembre relata, segundo Gurovitz (2012), como é sua visão do corpo que se faz presente na forma da cadeira: "o homem nasce do corpo feminino e passa a vida inteira tentando voltar a ele. É uma obsessão". As cadeiras Him e Her, lançadas em 2008 para a marca Casamania, é uma releitura da cadeira Panton com a forma literal masculina e a feminina nuas. $\mathrm{O}$ designer-artista ainda ressalta outra interpretação de seu olhar:

\footnotetext{
Quando um homem se senta na versão feminina ou uma mulher na versão masculina, surge um estranhamento muito interessante. É como vestir a pele do outro [...] Meu objetivo é eliminar a fronteira que existe entre o observador e a obra. Busco a proximidade, o contato. A arquitetura e as peças de design precisam permitir que o usuário interaja com elas. (GUROVITZ, 2012)
}

Com isso, conseguimos entender os nomes dados às cadeiras: "Him", dele, e "Her", dela, direcionando cada uma para seu usuário adequado.

Nas as fotografias tiradas com os modelos (Figura 12), observamos novas interpretações do design-artista, que marca seu trabalho com o devaneio, um estado de divagação do ser humano, sempre conectado a um contexto poético. 

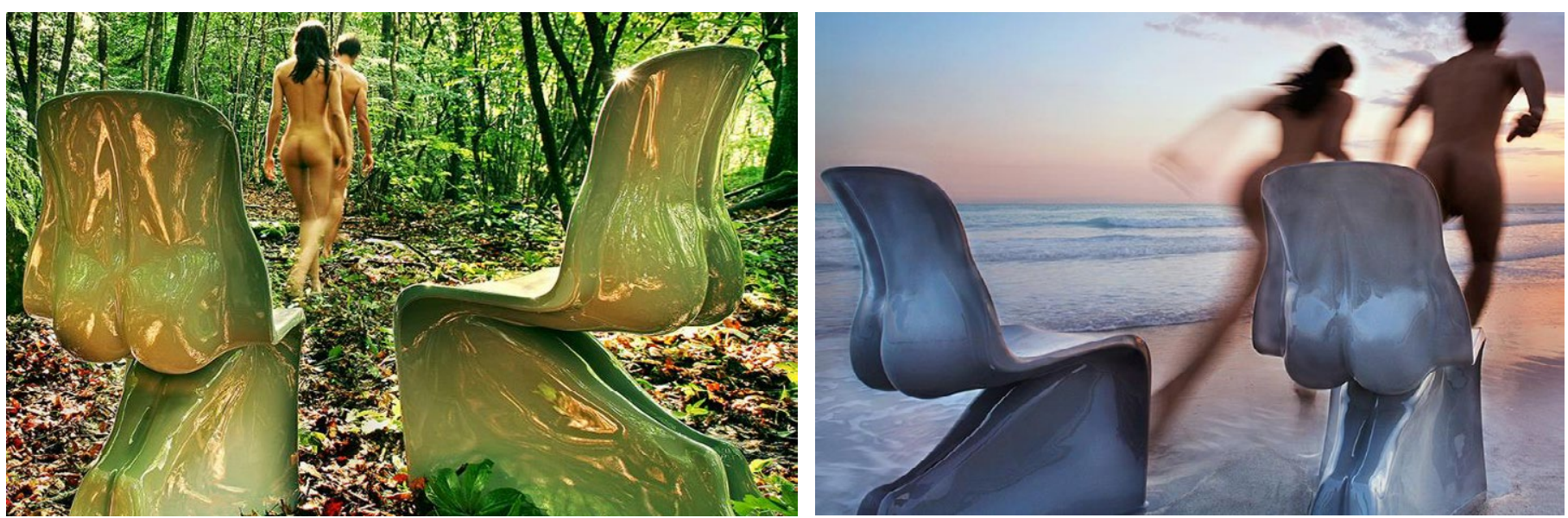

Fig 12. Cadeiras Him \& Her em um contexto poético

Fonte: Novembre e Casamania (2017)

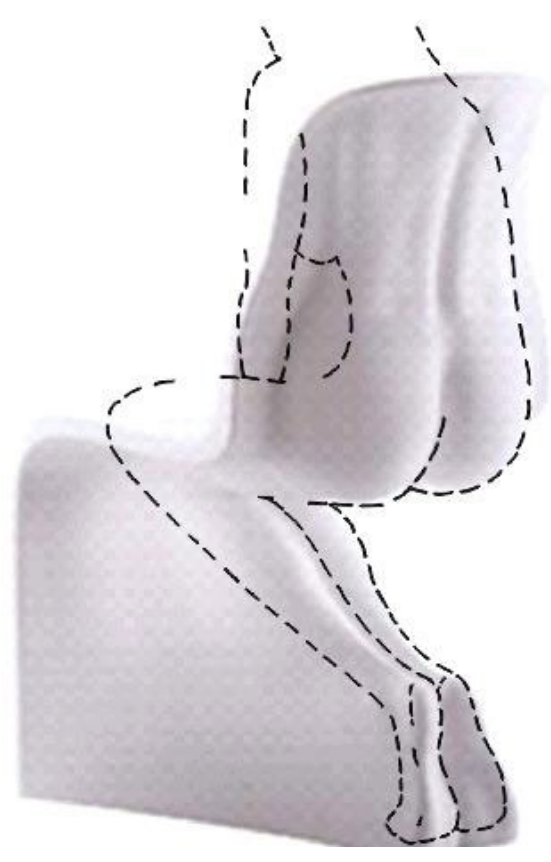

Fig 13. Estudo 4, Cadeiras Him \& Her (2008) Fonte: Elaborado pela autora.
From the Genesis Book: Then the LORD God formed a man from the dust of the ground and breathed into his nostrils the breath of life, and the man became a living being [...] Then the LORD God made a woman from the rib he had taken out of the man, and he brought her to the man [...] Adam and his wife were both naked, and they felt no shame.

Do Livro de Gênesis: Então o Senhor Deus formou um homem do pó da terra e soprou nas narinas o sopro da vida, e o homem tornou-se um ser vivo [...] Então o Senhor Deus fez uma mulher da costela que ele tinha tirado do homem, e ele a trouxe para o homem [...] Adão e sua esposa estavam ambas nus, e eles não sentiam nenhuma vergonha. (NOVEMBRE e CASAMANIA, 2017)

Como se pode perceber no Estudo 4, o encaixe da anatomia humana é perfeito, o que seguramente resulta em conforto e repouso, o corpo deixa o molde no plástico e, assim, registra sua silhueta, que constitui e dá forma à cadeira, proporcionando identidade e aproximação por gênero, como também uma empatia com tal semelhança.

Consideramos importante fazer uma síntese das cadeiras analisadas e as respectivas formas dos corpos nelas retratadas. Para isso, trazemos o Quadro 2, onde se observa todo o conjunto de corpos estudados nas referidas cadeiras, o que confirma o pressuposto: cadeira como retrato do corpo humano.

O movimento do corpo é um desígnio tanto do repouso quanto de seu deslocamento. Diante disso, percebemos que ele se encontra presente na cadeira de forma não estática, ou seja, não se encontra em uma só posição. Se a cadeira servisse somente para sentar, ela permaneceria em uma única forma que admitisse essa função. Mas, ao invés disso, também se coloca como corpo em constante oscilação, o que é explicitado nos Estudos de 1 a 4, realizados com a sobreposição do corpo, e nas Figuras 4,7,9,11, respectivamente. 
Se pensarmos a cadeira como um único objeto e as dez posturas estudadas, percebemos que ela se movimenta tanto quanto o corpo, em um ritmo no qual não se pode presumir qual seria o próximo passo.

Assim se faz também para as possibilidades das formas que uma cadeira pode gerar, tudo dependendo de seu contexto e da experiência de seu criador.

A intenção dos estudos não foi a de sobressair o corpo sobre a cadeira, mas determinar que ele se colocaria como "alma". As linhas tracejadas dão a noção de um corpo presente e ausente.

Para reforçar o que aqui tratamos, também construímos um quadro que detalha todas as ideias individuais das referidas cadeiras (Quadro 2). Conseguimos entender, assim, aspectos que nelas se repetem e que se relacionam com a forma do corpo. Nota-se que a figura mais escolhida como inspiração é a silhueta do corpo da mulher. Uma referência constante em duas cadeiras é a forma primitiva das estatuetas femininas, presentes nas linhas 1 e 2. São comuns a todas as cadeiras as curvas sinuosas e as referências ao corpo humano, utilizado como molde para sua composição, o que é indicado nas linhas 3 e 4.

Confirma-se, assim, o que pressupomos: a cadeira como retrato do corpo humano, que faz dela um suporte para transmitir sua presença, materializada através da forma.

\section{Considerações Finais}

"A cadeira possui uma corporeidade própria" (CORRÊA; SILVA, 2013, p.14), admitindo novas experimentações e sentidos que atingem uma dimensão imaterial de informação. Relaciona-se como objeto de desejo quando sua forma se assemelha à silhueta humana, sendo, assim, uma extensão do próprio "eu", que se faz presente com características visuais morfológicas. $\mathrm{O}$ transpor dessas características funciona como ferramentas para os designers-artistas, que se aproveitam dessa tendência e configuram seus artefatos propondo novos rumos para se constituir uma forma que vá além da sua funcionalidade técnica e agregue ao objeto a aspectos significativos, subjetivos e cognitivos.

À medida que concluímos esse pensamento, podemos notar que há uma relação entre arte e design, devido a suas características. Apesar de existirem como conceitos individuais, eles interagem em uma veia artística que configura um transporte de forma humana. Propõe a academia uma inovação projetiva de linguagem através do olhar atento a formas corporais acentuadas para os objetos, produzindo-se, assim, uma densidade poética que carrega discursos verbais, imagéticos e híbridos.

Compreendemos, aqui, que a cadeira também funciona como um meio de idealização da forma do corpo, pois ela modela e seleciona princípios que são transfigurados por seus designers- artistas, carregando significados e ideologias que norteiam o percurso da sociedade através desse objeto. 
Uma das contribuições desta pesquisa foi demonstrar a utilização do corpo como imagem de valor universal, através do qual ele constitui um desejo da forma que se indicia na cadeira, ocasionando novas percepções sensoriais. De acordo com esse pensamento, acreditamos que existe uma relação do corpo com os objetos, e a cadeira interage de maneira física como também se espelha na sua forma, criando um vínculo intimista e ambivalente, ao exprimir e gerar uma morfologia que destila uma polissemia de sentidos, ao mesmo tempo éticos e estéticos, explicitados nos estudos de identificação da forma do corpo retratado nas cadeiras analisadas. Portanto, gera- se um corpo-forma ou forma-corpo que resulta no desenho da cadeira.

\begin{tabular}{|c|c|c|c|c|c|}
\hline № & CADEIRA & CORPO & $\begin{array}{l}\text { COMPO. DE } \\
\text { ESTRUTURA }\end{array}$ & $\begin{array}{c}\text { CONCEITOS DO } \\
\text { DESIGNER/ARTISTA }\end{array}$ & $\begin{array}{c}\text { RELAÇÃO DO CORPO COM } \\
\text { A CADEIRA }\end{array}$ \\
\hline 1 & & & $\begin{array}{l}\text { - Tipo concha. } \\
\text { - Plástico } \\
\text { reforçado com } \\
\text { fibra de vidro. } \\
\text { - Base cromada e } \\
\text { pés de carvalho } \\
\text { natural. }\end{array}$ & $\begin{array}{l}\text { - Romper com as } \\
\text { contradições e as } \\
\text { formas engessadas. } \\
\text { - Exploraçãa de } \\
\text { materiais para fazer } \\
\text { formas orgânicas, } \\
\text { com curvas } \\
\text { sinuosas. } \\
\text { - Filosofia: o bom } \\
\text { design deve ser } \\
\text { accessivel a todos. } \\
\text { - Garantir economia } \\
\text { através de peças } \\
\text { únicas para } \\
\text { empilhamento. }\end{array}$ & $\begin{array}{l}\text { - Exibir elegância. } \\
\text { - Permitir várias posições } \\
\text { sentadas e reclinadas. } \\
\text { - Formas orgânicas que se } \\
\text { assemelham ao corpo, } \\
\text { inspiradas pela escultura } \\
\text { Floating Figure (figura } \\
\text { flutuante) do artista } \\
\text { Gaston La Chaise, que se } \\
\text { inspirou nas estatuetas } \\
\text { primitivas femininas. }\end{array}$ \\
\hline 2 & & & $\begin{array}{l}\text { - Espuma de } \\
\text { poliuretano, } \\
\text { moldado com } \\
\text { tecido elástico. } \\
\text { - Comprimida em } \\
\text { um décimo de } \\
\text { seu tamanho } \\
\text { total e se } \\
\text { expande quando } \\
\text { a embalagem a } \\
\text { vácuo era } \\
\text { rompida. }\end{array}$ & $\begin{array}{l}\text { - Simbolizar a } \\
\text { mulher sujeita a } \\
\text { sociedade. } \\
\text { - Inovar através da } \\
\text { pesquisa de } \\
\text { materiais e } \\
\text { tecnologia. } \\
\text { - Abuso de cores. - } \\
\text { Móvel da } \\
\text { transformação. }\end{array}$ & $\begin{array}{l}\text { - As formas geométricas e } \\
\text { curvilineas marcam a } \\
\text { presença feminina de } \\
\text { corpo acolhedor, que } \\
\text { envolve em um "abraço } \\
\text { uterino". } \\
\text { - Demonstra sensualidade. } \\
\text { - Molda-se em torno do } \\
\text { corpo. } \\
\text { - Projetada para parecer } \\
\text { com o formato das } \\
\text { estatuetas primitivas } \\
\text { femininas. }\end{array}$ \\
\hline 3 & & & $\begin{array}{l}\text { - Molde de gesso } \\
\text { de um corpo } \\
\text { masculino. } \\
\text { - Plástico. }\end{array}$ & $\begin{array}{l}\text { - Repertório no } \\
\text { espirito de revolta e } \\
\text { engajamento } \\
\text { político. } \\
\text { - Incorporar objetos } \\
\text { cotidianos e } \\
\text { referências à cultura } \\
\text { pop. } \\
\text { - Criar um espaço } \\
\text { para quem quer } \\
\text { viver de uma forma } \\
\text { alternativa. }\end{array}$ & $\begin{array}{l}\text { - Fisicalidade e uma } \\
\text { presença humana que } \\
\text { reporta ao homem. } \\
\text { - Imagem de um corpo } \\
\text { transportado para o } \\
\text { objeto cadeira. } \\
\text { - Escultura de um corpo } \\
\text { sentado. }\end{array}$ \\
\hline 4 & & & - Plástico. & $\begin{array}{l}\text { - Criações uma } \\
\text { grande carga } \\
\text { poética. } \\
\text { - Discussões sociais } \\
\text { e culturais. }\end{array}$ & $\begin{array}{l}\text { - Assemelham-se a } \\
\text { silhuetas masculinas e } \\
\text { femininas. } \\
\text { - "O homem nasce do } \\
\text { corpo feminino e passa a } \\
\text { vida inteira tentando } \\
\text { voltar a ele. É uma } \\
\text { obsessão." } \\
\text { - Releitura da Cadeira } \\
\text { Panton. } \\
\end{array}$ \\
\hline
\end{tabular}

Quadro 2. Análise das Cadeiras 
A cadeira como retrato do corpo humano: A representatividade do objeto para os designers/artistas

\section{Referências}

BARTOLETTI, Laurence. Homme/Man Chair (copy 24), 1970: Ruth Francken. Disponível em: <http://collection.design-museum.de/\#/en/object/147295?_k=e8kss5>. Acesso em: 31 mar. 2017. CAPPELLINI (Org.). Fábio Novembre. 2017. Disponível em: <https://www.cappellini.it/ en/designer/fabio- novembre>. Acesso em: 29 jun. 2017.

CENTER, Walker Art (Org.). Dance Works I: Merce Cunningham / Robert Rauschenberg. 2012. Disponível em: <https://walkerart.org/calendar/2011/dance-works-i-merce-cunningham-robert-rausche>. Acesso em: 29 jun. 2017.

CORRÊA, M.; SILVA, C. Os objetos e seus usos. Cultura Visual, Salvador, v. 19, p.11-26, jul. 2013. Edufba. CORSINI, Lorenzo. Gaetano Pesce: sobre. 2015. Disponível em: <http://www. gaetanopesce.com/>. Acesso em: 28 jun. 2017.

DESIGN MUSEUM (Ed.). Cinquenta cadeiras que mudaram o mundo. Belo Horizonte: Autêntica Editora, 2010.

DESIGN MUSEUM (Ed.). Como criar uma cadeira. Belo Horizonte: Editora Gutenberg, 2011. DIVISARE (Org.). Studio Fabio Novembre: I HAVE A LIFESTYLE. 2017. Disponível em: <https:// divisare.com/projects/292232-studio-fabio-novembre-pasquale-formisano-i-have-a-lifestyle>. Acesso em: 29 jun. 2017.

FARIA, Ítalo Rodrigues. Metáforas, ou por exemplo as cadeiras. 2009. Disponível em: <https://www2.dti.ufv.br/danca_teatro/evento/apresentacao/artigos/gt3/italo.pdf>. Acesso em: 03 jun.2017.

GIU. Poltrona UP5 di Gaetano Pesce. 2012. Disponível em: <https://tecmatied.wordpress. com/2012/06/10/poltrona-up5-di-gaetano-pesce/>. Acesso em: 28 jun. 2017. GUROVITZ, Lucia. Fabio Novembre: Um designer que ama as mulheres. 2012. Disponível em: <http://casaclaudia.abril.com.br/profissionais/fabio-novembre-um-designer-que-ama-as-mulheres/>. Acesso em: 29 jun. 2017.

MATESCO, Viviane. Corpo, imagem e representação. Rio de Janeiro: Jorge Zahar, 2009.

MOMA. Gaston Lachaise: Mulher parada. 2004. Disponível em: <https://www.moma.org/collection/works/81215>. Acesso em: 14 jun. 2017.

NOVEMBRE, Fabio; CASAMANIA. Him \& Her. 2017. Disponível em: <http://www.novembre. it/himher/>. Acesso em: 29 jun. 2017.

STUDIOS, T-sign (Org.). La Chaise. 2017. Disponível em: <http://www.eamesoffice.com/the-work/la- chaise/>. Acesso em: 26 abr. 2017.

STUNGO, Naomi. Charles and Ray Eames. São Paulo: Cosac \& Naify Edições, 2000. 80 p. 